\title{
Activated Biochar-Based Metal Catalysts for Steam Reforming of Pyrolysis Bio-Oil Model Compound ${ }^{+}$
}

\author{
Christian Di Stasi 1,*, Marta Cortese ${ }^{2}$, Gianluca Greco ${ }^{1}$, Belén González ${ }^{1}$, Vincenzo Palma ${ }^{2}$ and \\ Joan J. Manyà ${ }^{1}$ \\ 1 Aragón Institute of Engineering Research (I3A), Technological College of Huesca, University of Zaragoza, \\ crta. Cuarte s/n, Huesca, E-22071, Spain; greco@unizar.es (G.G); belenglez@unizar.es (B.G); \\ joanjoma@unizar.es (J.J.M). \\ 2 Department of Industrial Engineering, University of Salerno, Via Giovanni Paolo II 132, 84084 Fisciano \\ (SA), Italy; marta.cortese90@gmail.com (M.C), vpalma@unisa.it (V.P). \\ * Correspondence: christiandistasi@unizar.es \\ + Presented at the 1st International Electronic Conference on Catalysis Sciences, 10-30 November 2020; \\ Available online: https://eccs2020.sciforum.net.
}

Published: 10 November 2020

\begin{abstract}
In this work, different biochar-based metal catalysts were tested for mid-temperature $\left(400-600{ }^{\circ} \mathrm{C}\right.$ ) acetic acid steam reforming. $\mathrm{K}, \mathrm{Co}, \mathrm{Ce}, \mathrm{Fe}$ and Ni were chosen as active phases for the production of the studied catalysts, which performances were evaluated in terms of acetic acid conversion, hydrogen yield, acetone yield, and stability. The best outcomes were obtained for the nickel-based catalysts, which exhibited high conversion $(>90 \%)$ along with insignificant deactivation rates. Nevertheless, for relatively low nickel loadings, a certain extent of coke deposition was deduced from the observed fluctuations in pressure drop. A $10 \mathrm{wt} . \%$ nickel loading appeared to be a reasonable tradeoff between activity and coke production. After the identification of the optimal loading, four bimetallic catalysts were produced with the aim of improving the original activity of the nickel-based one. The Cobalt-nickel catalysts showed the most stable behavior with a constant conversion degree $(98 \%)$ in the range of $475-600{ }^{\circ} \mathrm{C}$.
\end{abstract}

Keywords: biochar; physical activation; acetic acid; steam and dry reforming; bio-oil

\section{Introduction}

In the last years, a growing interest in using biochar as catalyst or catalyst support has arisen due to its relatively low cost and easy functionalization. Even though pristine biochar does not have a well-developed specific surface area and pore size distribution [1], which are essential features for a catalyst, they can be easily improved by means of further procedures. Among all the biochar upgrading procedures, $\mathrm{CO}_{2}$ controlled gasification is one of the most promising, since it is possible to obtain activated carbons with high surface area and expanded pore size distribution [2]. One of the most interesting field of application of the biochar-based catalysts is the upgrading of pyrolysis vapors through the conversion of the condensable products (bio-oil) into permanent gases via catalytic steam reforming [3-5]. The specific aim of this work is to produce biochar-based catalyst for pyrolysis vapors upgrading starting from binder-free wheat straw pellets. For this purpose, the selected biomass was first pyrolyzed under $\mathrm{N}_{2}$ atmosphere and then activated with $\mathrm{CO}_{2}$ at $700{ }^{\circ} \mathrm{C}$ and 1.0 MPa. These activated biochars were then loaded with different percentages of $\mathrm{K}, \mathrm{Fe}, \mathrm{Co}, \mathrm{Ce}$ and $\mathrm{Ni}$ in order to produce mono and bimetallic catalysts to be tested for mid-temperature $\left(400-600{ }^{\circ} \mathrm{C}\right)$ steam reforming of acetic acid, a pyrolysis bio-oil model compound.

\section{Materials and Methods}


The biochar used in this study was produced by slow pyrolysis of binder-free wheat straw pellets ( $9 \mathrm{~mm}$ OD and 10-13 $\mathrm{mm}$ long). More details about the pyrolysis set up can be found in our previous work [6]. The pristine biochar, which had an extremely low specific surface area $\left(2 \mathrm{~m}^{2} \mathrm{~g}^{-1}\right)$, was physically activated with pure $\mathrm{CO}_{2}$ at $700{ }^{\circ} \mathrm{C}$ and $1.00 \mathrm{MPa}$ in order to increase its textural properties (specific surface area and pore size distribution). Once activated, the samples were employed as supports for the production of different carbon-based metallic catalysts. The active phases were deposited on the support via wet impregnation, using $\mathrm{Fe}\left(\mathrm{NO}_{3}\right)_{3} \cdot 9 \mathrm{H}_{2} \mathrm{O}, \mathrm{Ni}\left(\mathrm{NO}_{3}\right)_{2} \cdot 6 \mathrm{H}_{2} \mathrm{O}$, $\mathrm{Co}\left(\mathrm{NO}_{3}\right)_{2} \cdot 6 \mathrm{H}_{2} \mathrm{O}, \mathrm{Ce}\left(\mathrm{NO}_{3}\right)_{3} \cdot 6 \mathrm{H}_{2} \mathrm{O}$ and $\mathrm{KNO}_{3}$ as precursors of the metallic active phase. Briefly, the activated biochar was impregnated with an aqueous solution of the precursor salt containing the desired loading of active phase and then stirred at $60{ }^{\circ} \mathrm{C}$ until complete water evaporation. The impregnated biochar was then dried overnight at $110^{\circ} \mathrm{C}$. Prior to the steam reforming experiments, the catalysts were heated up to $600{ }^{\circ} \mathrm{C}$ at $5^{\circ} \mathrm{C} \mathrm{min}^{-1}$ under reducing atmosphere $\left(\mathrm{Ar} / \mathrm{H}_{2}, 95 / 5\right.$ vol.\%) in order to simultaneously decompose the precursor salt and reduce the resulting oxides. These conditions were kept for 2 hours to assure complete decomposition/reduction of the precursors. The bimetallic catalysts were prepared in four steps: (1) deposition of the first precursor; (2) decomposition/reduction; (3) impregnation of the second precursor; and (4) final calcination/reduction. Table 1 lists all the biocharbased catalysts produced and the nomenclature used.

Table 1. Summary of the nomenclature used in the present study.

\begin{tabular}{ccc}
\hline \multicolumn{3}{c}{ Monometallic } \\
\hline Sample & Active Phase & Load (wt.\%) \\
BC & $/$ & $/$ \\
BCFe & $\mathrm{Fe}$ & 7 \\
BCCo & $\mathrm{Co}$ & 7 \\
BCCe & $\mathrm{Ce}$ & 7 \\
BCK & $\mathrm{K}$ & 7 \\
BCNi7 & $\mathrm{Ni}$ & 7 \\
BCNi4 & $\mathrm{Ni}$ & 4 \\
BCNi10 & $\mathrm{Ni}$ & 10 \\
\hline \multicolumn{3}{c}{} \\
\hline Sample & Bimetallic \\
BCFeNi & $\mathrm{Fe} / \mathrm{Ni}$ & Load (wt.\%) \\
BCCoNi & $\mathrm{Co} / \mathrm{Ni}$ & $7 / 10$ \\
BCCeNi & $\mathrm{Ce} / \mathrm{Ni}$ & $7 / 10$ \\
BCKNi & $\mathrm{K} / \mathrm{Ni}$ & $7 / 10$ \\
\hline
\end{tabular}

Catalytic tests were carried out in a tubular fixed bed reactor (made of AISI 316-L stainless steel, $370 \mathrm{~mm}$ long and $9 \mathrm{~mm} \mathrm{ID)} \mathrm{placed} \mathrm{in} \mathrm{an} \mathrm{electric} \mathrm{tubular} \mathrm{furnace.} \mathrm{Around} 1 \mathrm{~g}$ of sample was placed inside the reactor and packed with an inert filler (Kaowool тм fiber). A K-type thermocouple was placed in the center of the catalytic bed to monitor the system temperature. The acetic acid $(\mathrm{AcOH})$ used for the screening of the catalysts performance was diluted with bi-distilled water to achieve a steam to carbon molar ratio (S/C) of 4 [6]. The liquid was stored in a pressurized tank and fed to an evaporator by means of a liquid mass flow controller. The resulting gaseous blend was then mixed with $\mathrm{Ar}$ and delivered to the reactor. The steam reforming experiments were carried out at different temperatures in the range of $400-600{ }^{\circ} \mathrm{C}$ (at a heating rate of $5{ }^{\circ} \mathrm{C} \mathrm{min}-1$ ) and maintaining a contact time between the gas phase and the catalytic bed of $135 \mathrm{~ms}$ (considering a bed void fraction of 0.5). The composition of the outlet gas was monitored using a quadrupole mass spectrometer-based gas analyzer (Hiden QGA), which was able to measure, in real time, the concentrations of the main outlet products. The evolution of the pressure drop along the reactor was measured by means of a differential pressure sensor. The performances of the different catalysts tested were evaluated by comparing them in terms of $\mathrm{AcOH}$ conversion $\left(\mathrm{X}_{\mathrm{ACOH}}\right)$, hydrogen yield $\left(Y_{\mathrm{H} 2}\right)$ and acetone yield $\left(Y_{A c}\right)$, as defined in Equations (1)-(3), respectively, with $F_{i}$ representing the molar flowrate of the " $\mathrm{i}$ " species. 


$$
\begin{gathered}
\mathbf{X}_{\mathrm{AcOH}}=\left(\mathrm{F}_{\mathrm{AcOH}, \text { in }}-\mathrm{F}_{\mathrm{AcOH}, \text { out }}\right) \mathrm{F}_{\mathrm{AcOH}, \text { in }}{ }^{-1} 100, \\
\mathbf{Y}_{\mathrm{H} 2}=\mathrm{FH}_{\mathrm{H} 2 \text {, out }}\left(4 \mathrm{~F}_{\mathrm{AcOH}, \text { in }}\right)^{-1} 100, \\
\mathbf{Y}_{\mathrm{Ac}}=2 \mathrm{~F}_{\mathrm{Ac}, \text { out }} \mathrm{F}_{\mathrm{AcOH}, \text { in }^{-1}} 100,
\end{gathered}
$$

\section{Results and Discussion}

\subsection{Monometallic Catalysts}

The first test was carried out using only the activated biochar as catalytic bed in order to evaluate the effects that the support alone had on the conversion of acetic acid. The results, which are displayed in Figure 1a (dashed line), showed that, even though in the first stages of the experiment the conversion reached around $95 \%$, the deactivation was almost instantaneous. The same behavior was observed also in the case of the BCCe catalyst, which underwent even faster deactivation. Severe instability was also observed for BCCo and BCK catalysts. On the other hand, the iron-based catalyst, showed a decrease in activity during the first minutes of the experiment, stabilizing after $30 \mathrm{~min}$ at a steady conversion value of around 50\%. Since the pressure drop along the reactor was almost constant (as shown in Figure 1b), such decreasing trend may be ascribed to sintering phenomena occurring during the test. The best results in terms of stability were obtained for the Ni-based catalysts, which showed almost no-deactivation during the $60 \mathrm{~min}$ long experiment (see Figure 1a). In particular, a conversion of around $95 \%$ was achieved for the $\mathrm{BCNi7}$ material. The differences among the three samples could be related to different dispersion degrees of $\mathrm{Ni}$ on the support. In general, a small metal loading can lead to a better dispersion of the active phase on the support surface, leading to higher conversion values [7]. From Figure 1b, it can be observed that for both the $\mathrm{BCNi7}$ and BCNi4 catalysts, which had the best results in terms of acetic acid conversion, a relatively high coke deposition rate was deduced. Hence, these materials are not suitable for long-time applications. The BCNi10 material, instead, showed an almost constant pressure drop value, indicating that a high nickel loading was able to hinder the coke formation. Furthermore, even though the $\mathrm{BCNi} 4$ material showed a slightly higher conversion than that of $\mathrm{BCNi10}$, the resulting hydrogen yield resulted to be lower.
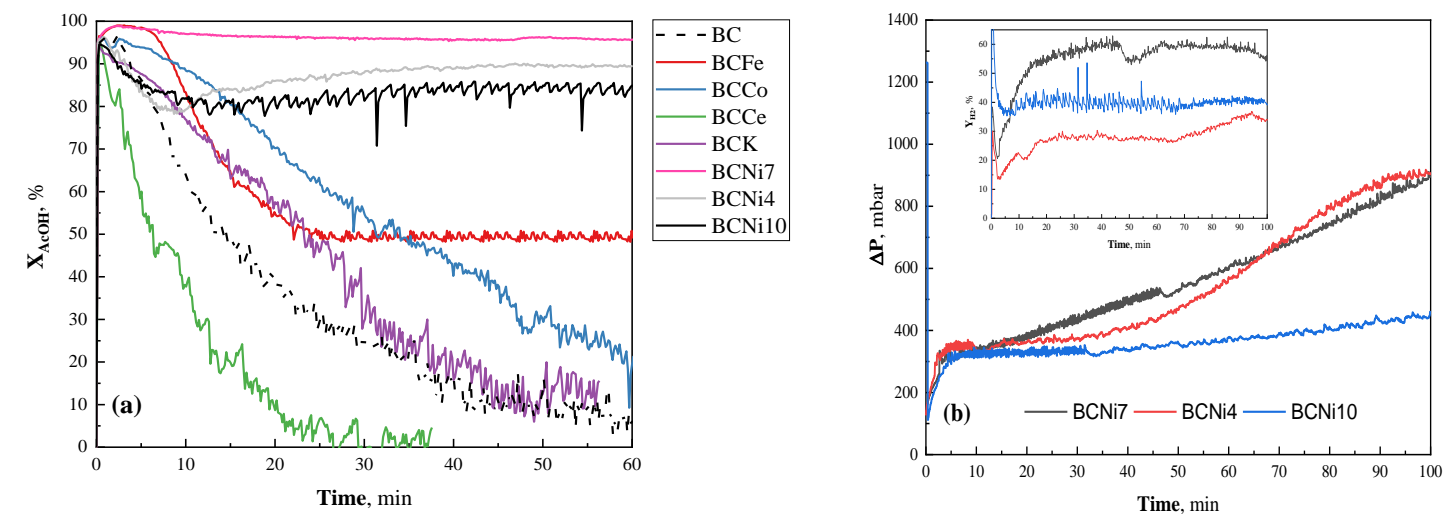

Figure 1. Results obtained for the acetic acid steam reforming at $600{ }^{\circ} \mathrm{C}$ using biochar-based monometallic catalysts. (a) Acetic acid conversion obtained for different catalysts; (b) Comparison of the pressure drop evolutions and $\mathrm{Y}_{\mathrm{H} 2}$ during the tests of the three Ni catalysts.

\subsection{Bimetallic Catalysts}

In light of the results obtained from the preliminary tests, it was established that, for our purpose, the most suitable active phase was nickel and, in particular, a loading of $10 \mathrm{wt} . \%$ guaranteed an acceptable acetic acid conversion and a relatively low deposition of coke. This stage of the study was aimed to improve the performance of the nickel-based catalyst, adding a second active phase, 
trying to obtain higher acetic acid conversions and minimize the coke deposition rate. Figure 2 shows the outcomes achieved for three of the four produced catalysts. The results obtained for the potassium-nickel catalysts (BCKNi) were not displayed, since it resulted to be highly unstable, showing a fast deactivation due to coke formation, which made such catalyst unsuitable for steam reforming applications. It can be observed that the reforming temperature greatly influenced the acetic acid conversion for both the BCFeNi and BCCeNi catalysts, with an expected maximum, at 600 ${ }^{\circ} \mathrm{C}$, of $80 \%$ and $97 \%$, respectively. On the other hand, the best results were obtained for the BCCoNi catalyst, which showed a constant conversion value of $98 \%$ in the whole range from 475 to $600{ }^{\circ} \mathrm{C}$. Despite the fact that the conversion remained constant, the hydrogen yield decreased from $62 \%$ (at $600{ }^{\circ} \mathrm{C}$ ) to $50 \%$ (at $500{ }^{\circ} \mathrm{C}$ ), suggesting a change in the reaction mechanism. As observed for the acetic acid conversion, the acetone yields also resulted to be closely dependent on both the catalyst and operating temperature. Among the three catalysts, the BCCeNi material led to the highest yield of acetone at temperatures below $500{ }^{\circ} \mathrm{C}$. Since very low acetone yields were observed when the BCCoNi catalyst was used at $500{ }^{\circ} \mathrm{C}$, it can be concluded that this material exhibited a high selectivity toward steam reforming. A stability test was carried out for the most promising catalyst (BCCoNi). The experiment started at $600{ }^{\circ} \mathrm{C}$ until stabilization and then the system was firstly cooled down to $500{ }^{\circ} \mathrm{C}$ (at $5^{\circ} \mathrm{C} \mathrm{min}^{-1}$ ) and the conditions kept for $15 \mathrm{~min}$. After that, the system was cooled down to $400{ }^{\circ} \mathrm{C}$, at the same cooling rate, and kept at this temperature for $15 \mathrm{~min}$. Finally, the system was then heated up to $600{ }^{\circ} \mathrm{C}$. As shown in Figure 3, the conversion remained stable at its maximum value from $600{ }^{\circ} \mathrm{C}$ to $475{ }^{\circ} \mathrm{C}$. The pressure drop remains constant during the first phase at $600{ }^{\circ} \mathrm{C}$ and gradually increased when temperature decreased. This fact, in addition to the observed production of acetone, could suggest a certain degree of coke formation. When the reactor was heated up again, the pressure drop increased again until the set temperature was reached. Nevertheless, the final conversion was the same that that measured for the fresh catalyst, indicating an almost negligible deactivation.
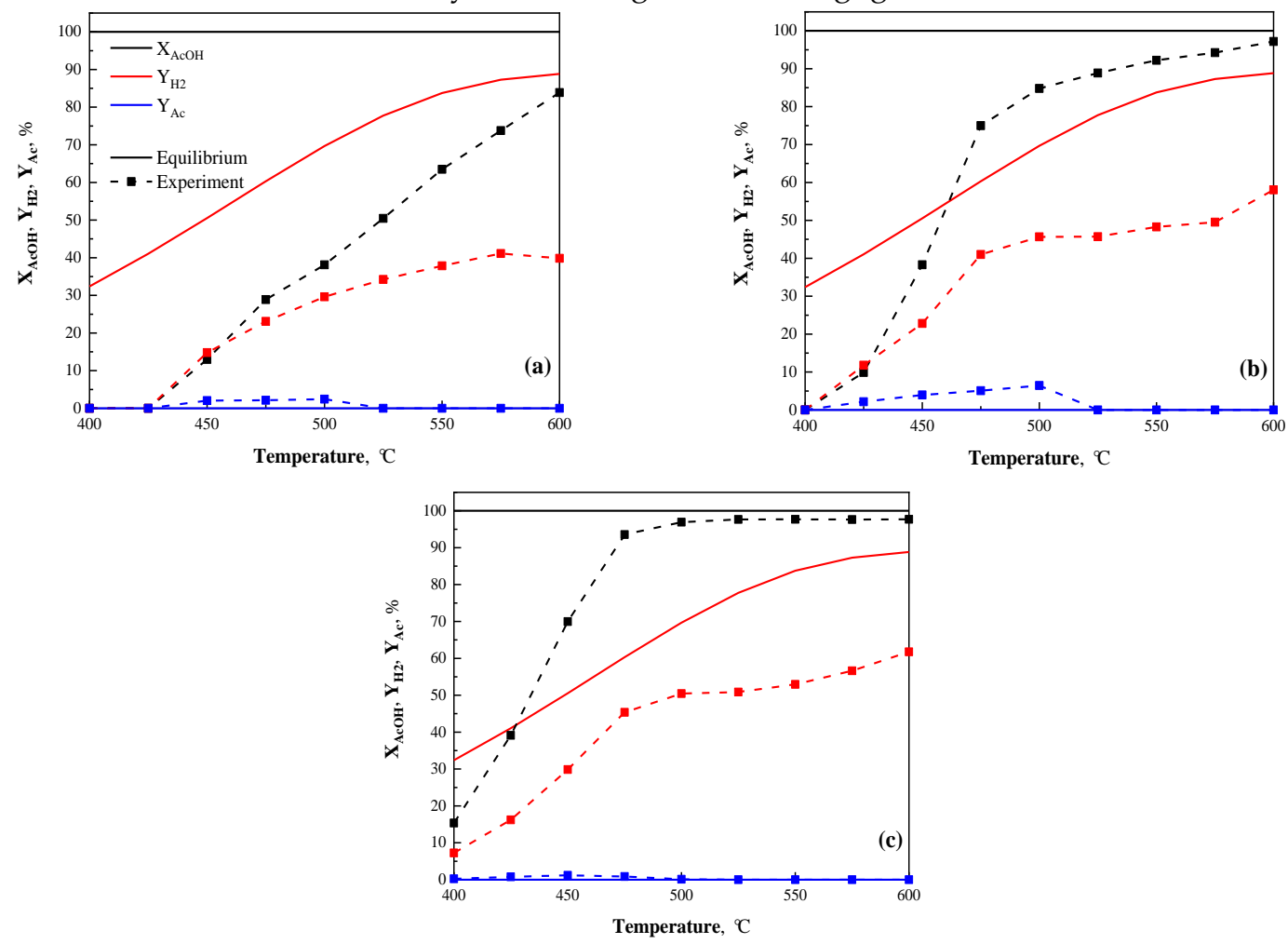

Figure 2. Acetic acid conversion, $\mathrm{H}_{2}$ yield, and acetone yield reported as function of temperature for different bimetallic catalysts: (a) BCFeNi; (b) BCCeNi; (c) BCCoNi. 


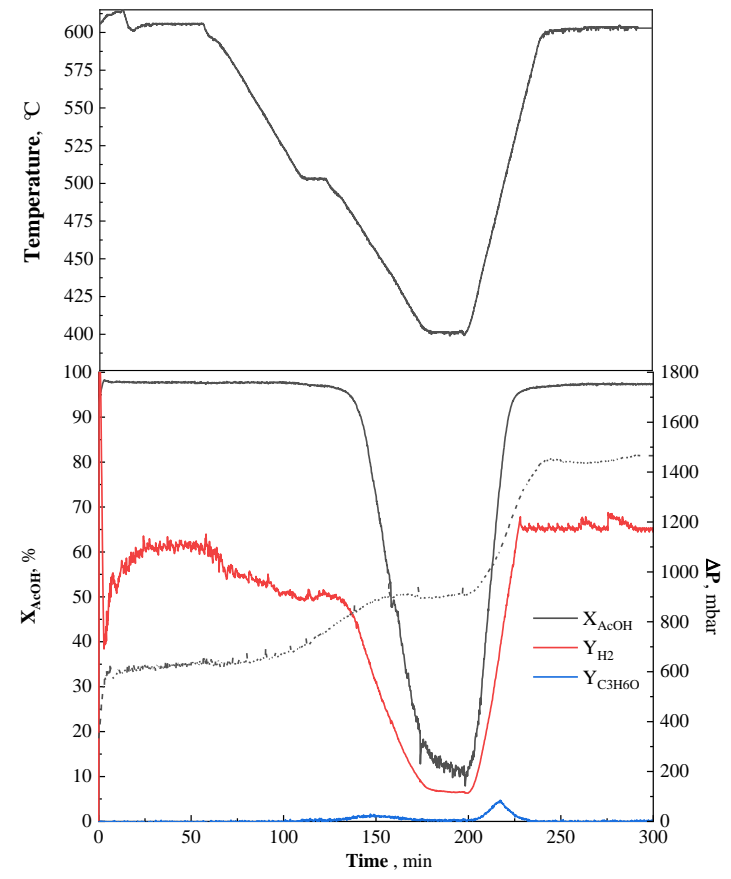

Figure 3. Cycling stability test of BCCoNi for steam reforming of acetic acid at different temperatures $\left(400-600{ }^{\circ} \mathrm{C}\right)$. In the plot are showed the $\mathrm{X}_{\mathrm{ACOH}}, \mathrm{Y}_{\mathrm{H} 2}, \mathrm{Y}_{\mathrm{AC}}$ and pressure drop evolution during the experiment.

\section{Conclusions}

From the results reported above, we can conclude that activated biochar can successfully be employed as support for the production of metal catalysts. In fact, for acetic acid steam reforming at $600{ }^{\circ} \mathrm{C}$ applications, the nickel-based catalysts showed a negligible deactivation rate accompanied by a high acetic acid conversion. In particular, a loading of $10 \mathrm{wt} . \%$ of nickel guaranteed a conversion of $80 \%$ with low coke deposition. Furthermore, it was demonstrated that the performance of the nickelbased catalyst could be enhanced with the addition of a second metal, with which it was possible to increase the maximum conversion. Among the four tested bimetallic catalysts, the best results in terms of conversion degree and resistance against deactivation, were obtained for an activated biochar loaded with $7 \mathrm{wt} . \%$ of $\mathrm{Co}$ and $10 \mathrm{wt} . \%$ of Ni.

Author Contributions: Conceptualization, methodology, validation, formal analysis, investigation, data curation, writing - original draft, C.D.S. Conceptualization, data curation, methodology, investigation, resources, M.C. Data curation, methodology, investigation, resources, G.G. Resources, writing - review \& editing, project administration, B.G. Conceptualization, data curation, supervision, V.P. Conceptualization, data curation, supervision, project administration, J.J.M.

Funding: This project received funding from the European Union's Horizon 2020 research an innovation programme under the Marie Skłodowska-Curie grant agreement No 721991. The authors also acknowledge the funding from the Aragón Government (Ref. T22_20R), cofunded by FEDER 2014-2020 "Construyendo Europa desde Aragón".

Acknowledgments: The authors gratefully thank José Antonio Manso (UNIZAR) and Simona Renda (UNISA) for their help in the preparation and characterization of the samples.

Conflicts of Interest: The authors declare no conflict of interest.

\section{References}

1. Greco, G.; Videgain, M.; Di Stasi, C; González, B.; Manyà, J.J. Evolution of the mass-loss rate during atmospheric and pressurized slow pyrolysis of wheat straw in a bench-scale reactor. J Anal Appl Pyrolysis 2018, 136, 18-26, doi:10.1016/j.jaap.2018.11.007. 
2. Lahijani, P.; Zainal, Z.A.; Mohammadi, M.; Mohamed, A.R. Conversion of the greenhouse gas CO2 to the fuel gas CO via the Boudouard reaction: A review. Renew Sustain Energy Rev 2015, 41, 615-32, doi:10.1016/j.rser.2014.08.034.

3. Ma, Z.; Xiao, R.; Zhang, H. Catalytic steam reforming of bio-oil model compounds for hydrogen-rich gas production using bio-char as catalyst. Int J Hydrogen Energy 2016, 42, 3579-85, doi:10.1016/j.ijhydene.2016.11.107.

4. Liu, W.J.; Jiang, H.; Yu, H.Q. Development of Biochar-Based Functional Materials: Toward a Sustainable Platform Carbon Material. Chem Rev 2015, 115, 12251-85, doi:10.1021/acs.chemrev.5b00195.

5. Kaewpanha, M.; Guan, G.; Ma, Y.; Hao, X.; Zhang, Z.; Reubroychareon, P.; Abudula, A. Hydrogen production by steam reforming of biomass tar over biomass char supported molybdenum carbide catalyst. Int J Hydrogen Energy 2015, 40, 7974-82, doi:10.1016/j.ijhydene.2015.04.068.

6. Di Stasi, C.; Alvira, D.; Greco, G.; González, B.; Manyà, J.J. Physically activated wheat straw-derived biochar for biomass pyrolysis vapors upgrading with high resistance against coke deactivation. Fuel 2019, 255, 115807, doi:10.1016/j.fuel.2019.115807.

7. Sun, D.; Du, Y.; Wang, Z.; Zhang, J.; Li, Y.; Li, J.; Lu, J. Effects of CaO addition on Ni/CeO $\mathrm{Cl}_{2}-\mathrm{ZrO}_{2}-\mathrm{Al}_{2} \mathrm{O}_{3}$ coated monolith catalysts for steam reforming of N-decane. Int J Hydrogen Energy 2020, 45, 16421-31, doi:10.1016/j.ijhydene.2020.04.126.

Publisher's Note: MDPI stays neutral with regard to jurisdictional claims in published maps and institutional affiliations.

(C) 2020 by the authors. Submitted for possible open access publication under the terms and conditions of the Creative Commons Attribution (CC BY) license (http://creativecommons.org/licenses/by/4.0/). 